DOI 10.37882/2500-3682.2021.12.07

\title{
ПСИХОПРОФИЛАКТИКА ТРЕВОЖНОСТИ В СТРУКТУРЕ ЭМОЦИОНАЛЬНОГО НЕБЛАГОПОЛУЧИЯ ПОДРОСТКОВ, ОСТАВШИХСЯ БЕЗ ПОПЕЧЕНИЯ РОДИТЕЛЕЙ
}

\section{PSYCHOPROPHYLAXIS OF ANXIETY IN THE STRUCTURE OF EMOTIONAL DISTRESS OF ADOLESCENTS LEFT WITHOUT PARENTAL CARE}

E. Dubovik

S. Tarasova

Summary: The article considers the problem of anxiety as an indicator and manifestation of emotional distress of adolescents left without care; presents the results of a study of personal and situational anxiety, school anxiety of adolescents left without parental care; describes the program of psychoprophylaxis of anxiety as an indicator of emotional distress and presents the dynamics of anxiety indicators confirming its effectiveness.

Keywords: emotional distress, anxiety, emotional disorders, psychoprophylaxis, adolescents left without parental care.

\section{Дубовик Евгения Юрьевна}

К.nсх.н., дочент, ФГБОУВО «Красноярский государственный педагогический университет им. В.П. Астафьева», Красноярск duevur2015@mail.ru

тарасова Светлана Ивановна

Аспирант, ФГБОУ ВО «Красноярский государственный педагогический университет им. В.П. Астафьева»,

Красноярск

tsvetlana_i@mail.ru

Аннотация: В статье рассматривается проблема тревожности, как показателя и проявления эмоционального неблагополучия подростков, оставшихся без попечения; представлены результаты исследования личностной и ситуативной тревожности, школьной тревожности подростков, оставшихся без попечения родителей; описана программа психопрофилактики тревожности как показателя эмоционального неблагополучия и представлена динамика показателей тревожности, подтверждающая ее эффективность.

Ключевые слова: эмоциональное неблагополучие, тревожность, эмоциональные нарушения, психопрофилактика, подростки, оставшиеся без попечения родителей.

В исследовании А.С. Бомба было выявлены основные эмоциональные нарушения в подростковом возрасте. К доминирующим эмоциональным нарушениям были отнесены страхи, депрессия, тревожность, агрессия, эмоциональная неустойчивость и эмоциональное напряжение [1].

Теоретический анализ литературных источников показал, что проблема эмоционального благополучия и эмоциональных нарушений в подростковом возрасте является достаточно разработанной, однако проблема эмоционального неблагополучия подростков, оставшихся без попечения родителей в психолого-педагогических исследованиях представлена недостаточно, в большинстве исследований изучается эмоциональное благополучие детей, оставшихся без попечения родителей (С.М. Петрова, И.В. Коткова [8], Н.Н. Толстых, А.М. Прихожан [11], и др.)

Дети и подростки, оставшиеся без попечения родителей имеют особенности эмоционального развития, характеризующееся переживанием эмоционального дискомфорта, чувства незащищенности. Этому способствует специфика жизнеустройства детского дома (В.Н. Ослон [7]), которая заключается в ограниченном количестве контактов вне предела детского дома (Е.Ю. Кри- 
воносова [5]), разрыв детско-родительских отношений, лишение семьи (К.М. Мымрикова [6]),отсутствие опоры ближайшего окружения (С.М. Петрова, И.В. Коткова [8]), групповая форма проживания подростков (Мымрикова К.М. [6], Г.А. Якубова [15]), различными видами деприваций, в которых отсутствует удовлетворение базовых психологических потребностей (С.А. Дмитриева [4], К.М. Мымрикова [6], Г.А. Якубова [15] и др.).

В качестве показателя эмоционального неблагополучия тревожность выступает в исследованиях А.М. Прихожан, С.С. Степанова, С.Л. Соловьевой Е.Н. Герасимовой, И.В. Фаустовой, С.Н. Гамовой, О.И. Шмыревой и др.

В исследованиях Е.Н. Герасимовой, С.Н. Гамовой, И.В. Фаустовой под эмоциональным неблагополучием понимается отрицательно окрашенная эмоциональная оценка собственного самочувствия, что проявляется переживании отрицательных состояний тревоги и страхов $[3,13]$.

Тревожность С.Л. Соловьева и относит к первичному показателю переживания эмоционального неблагополучия, когда фрустрируются удовлетворение потребностей, именно тревожность является реакцией на данную угрозу [9]. На возникновение тревожности как реакции на ожидание угрозы, опасности указывает А.М. Прихожан, подчеркивая эмоциональный дискомфорт и негативные переживания, как характеристики этого ожидания [10].

Тревожность Шмырева О.И. кладет в основу эмоционального неблагополучия в подростковом возрасте, которое проявляется в форме тревожно-фобического расстройства [14].

Поэтому актуальным является изучение тревожности как показателя эмоционального неблагополучия подростков, оставшихся без попечения родителей, и организации психопрофилактики ее возникновения.

Для выявления тревожности как показателя эмоционального неблагополучия подростков, оставшихся без попечения родителей и разработки программы психопрофилактики тревожности как показателя эмоционального неблагополучия было организовано экспериментальное исследование на базе Красноярского детского дома. В исследовании принимали участие 50 подростков в возрасте 12-16 лет, оставшихся без попечения родителей.

Для выявления проявлений в исследовании были использованы методики тест школьной тревожности Б. Филипса, методика Ч.Д. Спилбергера на выявление личностной и ситуативной тревожности.
Исследование тревожности позволило получить данные о личностной и ситуативной тревожности. По уровням личностной тревожности подростки, оставшиеся без попечения родителей распределились следующим образом: низкий уровень имеют 8\% подростков, средний уровень - 40\% подростков и высокий уровень - 52\% подростков. Согласно полученным результатам более половины подростков, оставшихся без попечения родителей, имеют высокий уровень личностной тревожности. Следовательно, для подростков личностная тревожность уже стала устойчивой индивидуальной характеристикой. Подростки, оставшиеся без попечения родителей предрасположены воспринимать угрозу различных ситуаций для собственной самооценки и жизнедеятельности, и под стрессовым воздействием у подростков появляется выраженная тревога.

По уровням ситуативной тревожности подростки, оставшиеся без попечения родителей, распределились следующим образом: низкий уровень имеют 10\% подростков, средний уровень - 54\% подростков и высокий уровень - 36\% подростков. Согласно полученным результатам, более половины подростков, оставшихся без попечения родителей, имеют средний уровень ситуативной тревожности, около трети подростков - высокий уровень ситуативной тревожности. Следовательно, в условиях стрессовой ситуации подростки, оставшиеся без попечения родителей, демонстрируют эмоциональное напряжение и беспокойство, выраженное в умеренной или выраженной интенсивности.

Эмоциональное неблагополучие подростков, оставшихся без попечения родителей в различных ситуациях учебно-образовательного процесса и во взаимодействии с учителями и сверстниками в ситуациях, связанных с осуществлением учебной деятельности, было изучено через исследование проявлений школьной тревожности и страхов, связанных с процессом учения (по методике Б. Филипса). Основные результаты

Согласно данным, представленным в таблице 4 и на рисунке 5 тревожность подростков, оставшихся без попечения родителей, по факторам, связанным с образовательным процессом, характеризуется следующими показателями.

По шкале «Переживание социального стресса» повышенную тревожность проявляют 14\% подростков, высокую тревожность - 24\% подростков, в рамках нормативного проявления тревожности находятся 62\% подростков. Отрицательное эмоциональное состояние, связанное с взаимоотношениями со сверстниками, переживают 38\% подростков, оставшихся без попечения родителей.

По шкале «Фрустрация потребности в достижении 
успеха» повышенную тревожность проявляют 30\% подростков, высокую тревожность - 18 \% подростков, в рамках нормативного проявления тревожности находятся 58\% подростков. При высоком уровне по данной шкале у подростков преобладающим является неблагоприятный психический фон, препятствующий удовлетворению потребности в достижении учебных успехов. Подростки с повышенным уровнем тревожности по данной шкале способны самостоятельно или с помощью других преодолеть фактуры образовательного процесса, фрустрирующие потребность в достижении учебных успехов.

По шкале «Страх самовыражения» повышенный уровень выраженности имеют 30\% подростков, высокий уровень - 20\% подростков, в рамках нормативного проявления страхов находятся 50\% подростков. Следовательно, половина исследуемых подростков, оставшихся без попечения родителей переживают негативные эмоции постоянно или в некоторых ситуациях, в которых необходимо раскрыться, показать себя и продемонстрировать свои качества, способности и другое необходимостью самораскрытия, предъявления себя другим, демонстрации своих возможностей.

По шкале «Страх ситуации проверки знаний» повышенный уровень выраженности имеют 24\% подростков, высокий уровень - 26\% подростков, в рамках нормативного проявления страхов находятся 50\% подростков. Половина подростков испытывают страх в случаях проверки знаний, который может вызываться негативными отметками, низкой уверенностью в своих знаниях, умениях, навыков, способностей, поэтому и вызывает тревогу само ожидание проверки знаний.

По шкале «Страх не соответствовать ожиданиям окружающих» повышенный уровень выраженности имеют 24\% подростков, высокий уровень - 28\% подростков, в рамках нормативного проявления страхов находятся $48 \%$ подростков. Более половины подростков, оставшихся без попечения родителей ориентируются на оценку себя, мыслей, своей деятельности, поведения другими (в подростковом возрасте - чаще на оценку со стороны сверстников), поэтому ожидание негативных оценок со стороны других вызывает тревогу у подростков, имеющих высокий и повышенных уровень страха не соответствовать ожиданиям окружающих.

По шкале «Низкая физиологическая сопротивляемость стрессу» повышенный уровень выраженности имеют 26\% подростков, высокий уровень - 16\% подростков, в рамках нормативного физиологического сопротивления стрессу находятся 58\% подростков. Следовательно, около трети подростков, оставшихся без попечения родителей в различных учебных стрессовых ситуациях, демонстрируют неадекватные эмоциональ- ные реакции, что связано с низкой стрессоустойчивостью.

По шкале «Проблемы и страхи в отношениях с учителями» повышенный уровень выраженности имеют 38\% подростков, высокий уровень - 18\% подростков, в рамках нормативного проявления страхов находятся $46 \%$ подростков. По данной шкале получены наиболее высокие показатели отклонения от нормативного переживания страхов и тревожности. Следовательно, 56\% подростков, оставшихся без попечения родителей испытывают негативные переживания по отношению их взаимодействия с учителями, по отношению к учителю, что в свою очередь сказывается на успешности освоения образовательной программы.

В целом, по шкале «Общая тревожность в школе» повышенную тревожность проявляют 26\% подростков, высокую тревожность - 22\% подростков, в рамках нормативного проявления школьной тревожности находятся 52\% подростков. Таким образом, у 48\% подростков общее эмоциональное состояние подростка, характеризуется проявлениями негативных переживаний разной интенсивностью и длительностью, или отрицательным эмоциональным фоном в различных ситуациях учебно-образовательного процесса и во взаимодействии с учителями и сверстниками в ситуациях, связанных с осуществлением учебной деятельности.

Полученные результаты позволили определить психолого-педагогические условия психопрофилактики тревожности как показателя эмоционального неблагополучия подростков, оставшихся без попечения родителей:

- большие психологические игры;

- настольные трансформационные игры;

- программа арт-терапии;

- техники МАК (метафорические ассоциативные карты);

— тренинг снижения тревожности подростков.

Для отреагирования негативных переживаний были использованы большие психологические игры «Эмоциональные загадки», «Чувства животных», «Объясняю, понимай» и др., направленные на развитие осознание негативных эмоциональных проявлений, снижение эмоциональной нестабильности.

Трансформационная игра позволяет актуализировать и осознать эмоции, которые на текущий момент, позволяет трансформировать деструктивную эмоцию в ресурсную, отреагировать ее. С целью снижения личностной и ситуативной тревожности использованы игры «Путешествие души» (автор М. Будякова), «Маленький принц» (автор Ю. Осадчая), «Сила» (автор А. Шкляева), «Сатори» (автор К. Типпинг). Игры позволяют повысить 
уверенность в себе, отработать умения совершать выбор и действовать без страха, тревоги.

Разработка программы арт-терапии, направленной на снижение тревожности как показателя и проявления неблагополучия исходила из следующих положений. В процессе творчества подросток выражает свои негативные эмоции и чувства, происходит перестройка отношения к ситуации и окружающим, снижение переживания угрозы, опасности, связанных с неприятными и травмирующими образами. Обсуждение с психологом продукта творческой деятельности (рисунка, песочной картины, истории (сказки) и др.), подросток учится преодолевать тревогу, бороться со страхами. Во время обсуждений действенно снижаются симптомы негативных переживаний.

Программа арт-терапии включает 10 занятий, продолжительность каждого занятия примерно 1,2-1,5 часа. Основные цели занятий: снижение самооценочной тревожности, развитие адекватного уровня притязаний; коррекция эмоциональных нарушений страхов и тревожности подростков; формирование позитивного опыта, усвоению групповых норм и ценностей; снижение уровня тревожности и повышение стрессоустойчивости; релаксация, снятие внутреннего контроля, развитие воображения, спонтанное самовыражение, снятие эмоционального напряжения; проработка эмоции страха; проработка и коррекция негативных переживаний, развитие уверенности в себе, самопознание и самосовершенствование; развитие самоинтереса, повышение самооценки, рефлексия различных «Я-схем», развитие креативности; развитие способности к взаимопониманию; повышение степени эмоциональной открытости участников.

Использование метафорических ассоциативных карт было направлено на помощь подросткам в осознании и отреагировании негативных эмоциональных переживаний тревоги. Использовались техники «У меня ничего не получается!» (автор Н. Борисова), техники «Линейка эмоций» с использованием карт «Anibi» (Автор: Макеева А.С.), техники «Сочинение сказки».

С целью снижения школьной тревожности у подростков до уровня «мобилизующей» тревоги применялся тренинг, включающий в себя 12 занятий, направленных на: осознание наличия тревожности у участников группы, на определение школьных ситуаций вызывающих тревожность; разрядку тревожности, связанной с различными учебными ситуациями и взаимодействия с учителями, отреагирования негативных переживаний; развитие навыков общения, повышение самооценки подростков, создание мотивации успеха в учебной деятельности.
Содержание тренинга составляют ситуационно-ролевые и развивающие игры, упражнения с игровыми элементами, психотерапевтические приемы (вербализация, визуализация, обратная связь, арт-терапевтические, сказкотерапевтические техники), групповое обсуждение, дискуссии, психогимнастические упражнения, направленные на снижение психоэмоционального напряжения и раскрепощение подростков.

Для проверки эффективности психопрофилактики тревожности, как показателя эмоционального неблагополучия подростков, оставшихся без попечения родителей, была проведена повторная диагностика.

После реализации модели психопрофилактики произошло снижение личностной тревожности: показатель высокого уровня снизился на 28\%, а показатель низкого уровня повысился на $30 \%$. После реализации модели подростки, оставшиеся без попечения родителей, имеют средний и низкий уровни личностной тревожности (по 38\% подростков на каждом уровне).

Подростки стали в меньшей степени воспринимать угрозу различных ситуаций для собственной самооценки и жизнедеятельности, и под стрессовым воздействием у подростков может появляться умеренная тревога. Однако данная динамика не является статистически значимой, следовательно выборки подростков по уровню личностной тревожности являются схожими.

По шкале «ситуативная тревожность» также произошла статистически значимая положительная динамика уровня тревожности, показатель высокого уровня снизился на $26 \%$, показатель низкого уровня повысился на 44\%. И после реализации модели психопрофилактики у подростков преобладает низкий уровень ситуативной тревожности - 54\% подростков. Высокую тревожность в стрессовой ситуации демонстрируют только 10\% подростков. Данные различия являются статистически значимыми на уровне $p<0,024$.

Следовательно, в условиях стрессовой ситуации подростки, оставшиеся без попечения родителей, демонстрируют эмоциональное спокойствие или беспокойство умеренной интенсивности.

Сравнение показателей школьной тревожности подростков, оставшихся без попечения родителей до и после реализации модели психопрофилактики эмоционального неблагополучия с помощью критерия U Манна-Уитни позволил определить статистически значимые различия по факторам школьной тревожности:

- общая тревожность $(U=246 ; p<0,029)$;

- страх самовыражения $(U=290 ; p<0,001)$;

- страх несоответствия ожиданиям окружающих $(U=196 ; p<0,024)$; 
- проблемы и страхи в отношениях с учителями $(U=268 ; p<0,021)$.

Рассмотрим статистически значимое изменение показателей школьной тревожности подростков, оставшихся без попечения родителей после реализации модели психопрофилактики эмоционального неблагополучия.

По шкале «Страх самовыражения» после реализации модели психопрофилактики эмоционального неблагополучия произошло снижение показателя повышенного уровня на $14 \%$, высокого уровня - на $12 \%$, в рамках нормативного проявления страхов находятся 76\% подростков. Следовательно, у преобладающего большинства подростков, оставшихся без попечения родителей (76\% подростков) снизился страх самовыражения, самораскрытия, отсутствуют, либо выражены незначительно негативные переживания в ситуациях, в которых необходимо показать себя и продемонстрировать свои качества, способности, демонстрации своих возможностей.

По шкале «Страх не соответствовать ожиданиям окружающих» после реализации модели психопрофилактики эмоционального неблагополучия произошло снижение показателя повышенного и высокого уровня тревожности на 24\%, в рамках нормативного проявления страхов находятся $62 \%$ подростков. Произошло снижение у подростков ожидания негативных оценок со стороны других, тревожности и страхов не оправдать ожидания окружающих.

По шкале «Проблемы и страхи в отношениях с учителями» после реализации модели психопрофилактики эмоционального неблагополучия подростков, оставшихся без попечения родителей произошло снижение показателя повышенного уровня на $12 \%$, высокого уровня - на 10\%. Показатель нормативного переживания тревожности повысился на 18\% и после психопрофилактики в рамках нормативного проявления страхов находятся 64\% подростков. Произошло снижение негативных переживаний при взаимодействии с учителями, страхи по отношению к учителю отсутствуют либо выражены незначительно.

В целом, по шкале «Общая тревожность в школе» после реализации модели психопрофилактики эмоционального неблагополучия подростков, оставшихся без попечения родителей наблюдается статистически значимая положительная динамика. Произошло снижение повышенного и высокого уровня на $20 \%$ и находятся в рамках нормативного проявления школьной тревожности 66\% подростков. Таким образом, произошло снижение негативного эмоционального состояния подростков, оставшихся без попечения родителей, связанных с ситуациями учебно-образовательного процесса, снизи- лось количество негативных переживаний и страхов и во взаимодействии с учителями и сверстниками в учебных ситуациях.

По показателю личностной и ситуативной тревожности:

- снизилась степень восприятия угрозы различных ситуаций для собственной самооценки и жизнедеятельности, и под стрессовым воздействием у подростков появляется умеренная тревога.

- преобладает низкий уровень ситуативной тревожности. В условиях стрессовой ситуации подростки, оставшиеся без попечения родителей, демонстрируют эмоциональное спокойствие или беспокойство умеренной интенсивности.

По показателю школьной тревожности:

- снизился страх самовыражения, самораскрытия, в ситуациях, в которых необходимо показать себя и продемонстрировать свои качества, демонстрации своих возможностей.

- произошло снижение у подростков ожидания негативных оценок со стороны других, тревожности и страхов не оправдать ожидания окружающих;

- произошло снижение негативных переживаний при взаимодействии с учителями, страхи по отношению к учителю отсутствуют либо выражены незначительно.

- произошло снижение негативного эмоционального состояния, связанных с ситуациями учебно-образовательного процесса, снизилось количество негативных переживаний и страхов и во взаимодействии с учителями и сверстниками в учебных ситуациях.

В заключение проведенного экспериментального исследования можно сделать следующие выводы:

1. Проявление негативных эмоциональных переживаний и беспокойства, такого как тревожность, составляют основу эмоционального неблагополучия личности.

2. Психопрофилактика тревожности в структуре эмоционального неблагополучия способствовала:

- снижению степени восприятия угрозы различных ситуаций для собственной самооценки и жизнедеятельности, и под стрессовым воздействием у подростков появляется умеренная тревога.

- преобладанию низкого уровня ситуативной тревожности. В условиях стрессовой ситуации подростки, оставшиеся без попечения родителей, демонстрируют эмоциональное спокойствие или беспокойство умеренной интенсивности.

- снижению страха самовыражения, саморас- 
крытия, в ситуациях, в которых необходимо показать себя и продемонстрировать свои качества, демонстрации своих возможностей.

- снижению у подростков ожидания негативных оценок со стороны других, тревожности и страхов не оправдать ожидания окружающих;

- снижению негативных переживаний при взаимодействии с учителями, страхи по отноше- нию к учителю отсутствуют либо выражены незначительно.

- снижению негативного эмоционального состояния, связанных с ситуациями учебно-образовательного процесса, снизилось количество негативных переживаний и страхов и во взаимодействии с учителями и сверстниками в учебных ситуациях.

\section{ЛИТЕРАТУРА}

1. Бомба, А.С. Проблема эмоциональных нарушений в подростковом возрасте / А.С. Бомба // Скиф. Вопросы студенческой науки. - 2018. - № 7(23). C. 83-89.

2. Выготский Л.С. Психология развития ребенка. - М.: Эксмо, 2005. - 320 с.

3. Герасимова Е.Н., Фаустова И.В. Изучение эмоционального неблагополучия современных детей старшего дошкольного возраста // Психология образования в поликультурном пространстве. - 2011. - Т. 2. - № 14. С. 43-47.

4. Дмитриева С.А. Психологическая коррекция эмоциональной сферы воспитанников детского дома // Вестник ТОГИРР0. - 2012. - № 2. - С. 1-165.

5. Кривоносова Е.Ю. Риски безопасности психологической среды в условиях детского дома // Novalnfo.Ru. 2018. - T. 1. - № 90. -C. $268-271$.

6. Мымрикова К.М. Эмоциональная депривация как условие развития социально - психологических трудностей общения у детей, воспитывающихся в детском доме // Матрица научного познания. - 2018. - № 4. - С. 126-129.

7. Ослон, В.Н. Жизнеустройство детей-сирот: профессиональная замещающая семья. М.: Генезис, 2006. - 368 с.

8. Петрова С.М., Коткова И.В. Коррекция эмоционального состояния детей - воспитанников детского дома в целях обеспечения их эмоционального благополучия и психологической безопасности // Герценовские чтения: психологические исследования в образовании. - 2019. - № 2. -C. 500-511.

9. Прихожан А.М. Изучение тревожности как переживания в контексте культурно-исторической концепции // Вестник РГГу. Серия: Психология. Педагогика. Образование. - 2006. - № 1. - С. 99-115.

10. Соловьева С.Л. Тревога и тревожность: теория и практика // Медицинская психология в России. 2012. № 6(17). С. 14.

11. Толстых Н.Н., Прихожан А.М. Психология подросткового возраста: Учебник и практикум / Н.Н. Толстых, А.М. Прихожан. - М.: ЮРАЙТ, 2020. - 406 с.

12. Фаустова И.В. Особенности психокоррекционной работы по преодолению эмоционального неблагополучия детей старшего дошкольного возраста // Психология образования в поликультурном пространстве. 2009. Т. 2. № 3-4. С. 71-76.

13. Фаустова И.В., Гамова С.Н. Эмоциональное благополучие ребенка как предпосылка развития его эмоциональной устойчивости // Современные проблемы науки и образования. 2016. № 6. С. 34-38

14. Шмырева О.И. Психологическая модель преодоления эмоционального неблагополучия в подростковом возрасте // Мир психологии. 2007. № 1 (49). C. 240-245.

15. Якубова Г.А. Психологические особенности пассивности эмоционального общения детей с депривацией из детских домов // Paradigmata poznani. 2017. № 2. C. 28-35. 